\title{
Association of Endometrial Carcinoma with Obesity and Diabetes Mellitus
}

\author{
Begum $\mathrm{SA}^{1^{*}}$, Mahmud $\mathrm{T}^{2}$, Amatullah $\mathrm{M}^{1}$ \\ ${ }^{I}$ Department of Gynecological Oncology, Bangabandhu Sheikh Mujib Medical University, Dhaka, \\ Bangladesh; 'Ibrahim Medical College and BIRDEM General Hospital, Dhaka, Bangladesh
}

\begin{abstract}
Background: Endometrial cancer, previously referred to as carcinoma of the uterus. The incidence of endometrial cancer is raising, due to improved screening causing fewer hysterectomies in ageing population. Several studies are going on to find out the association and effects between DM and DMrelated diseases, especially the cancer. Obesity and physical inactivity plays important role as modifiable determinants of insulin resistance, hyperinsulinaemia and diabetes. All these factors are also responsible for endometrial cancer.

Objectives: To find out the association between endometrial carcinoma with obesity and diabetes mellitus

Methods: This was a cross sectional and observational study, conducted among. 50 consecutive patients admitted as known case of endometrial carcinoma diagnosed by fractional curettage and endometrial biopsy and 50 consecutive patients having other common gynaecological problems in Bangabandhu Sheikh Mujib Medical University (BSMMU), Dhaka from January 2015 to December 2017.
\end{abstract}

Results: Out of 50 women having endometrial carcinoma, only $4 \%(n=2)$ having healthy BMI, $36 \%$ $(\mathrm{n}=18)$ were overweight, $60 \%(\mathrm{n}=30)$ were obese. Among 50 healthy women without endometrial carcinoma showed that $4 \%(\mathrm{n}=2)$ having underweight, $70 \%(\mathrm{n}=35)$ having healthy BMI, $14 \%(\mathrm{n}=7)$ having overweight and only $12 \%(\mathrm{n}=6)$ were obese. Regarding distribution of diabetes mellitus among study population, 50 women having endometrial carcinoma $26 \%(n=13)$ were diabetic and $74 \%(n=37)$ were non diabetic. 50 healthy women without endometrial carcinoma showed that $8 \%(\mathrm{n}=4)$ diabetic and $92 \%(\mathrm{n}=46)$ were non diabetic. Among total $17 \%(\mathrm{n}=17)$ diabetic patients, $76.5 \%(\mathrm{n}-13)$ having endometrial carcinoma and $23.5 \%(\mathrm{n}=4)$ were healthy having no endometrial carcinoma. Among $83 \%$ $(\mathrm{n}=83)$ women having no diabetes $55.4 \%(\mathrm{n}=46)$ were healthy having no endometrial carcinoma and $44.6 \%(\mathrm{n}=37)$ having endometrial carcinoma. Association between Diabetes mellitus and endometrial carcinoma was statistically significant $(p=0.017$ ). Having high BMI (overweight, obese) and diabetics had significant elevated risks of endometrial cancer, compared with non-overweight non-diabetic subjects.

Conclusion: Obesity, history of PCOS, physical inactivity and diabetes are the risk factors of endometrial carcinoma. So, it should be treated promptly these diseases to reduce risk factors. Moreover, strengthen public awareness to address these risk factors at earlier to reduce the cancer burden is recommended.

Keywords: Endometrial carcinoma, obesity, Diabetes, Physical inactivity.

\section{Introduction}

There were an estimated 18 million cancer cases around the world in 2018, of these 8.5 million cases were women according to data shown by World cancer research fund, American institute for cancer research. Bangladesh is a developing country that is facing many challenges, especially in the health sector. The sustainable Development Goals, set by the United Nations in 2015, identifying prevention and control of noncommunicable diseases as core priorities. ${ }^{1}$

*Correspondence: Dr. Shirin Akter Begum, Department of Gynecological Oncology, Bangabandhu Sheikh Mujib Medical University, Dhaka, Bangladesh; e-mail: shirin.bsmmu@gmail.com; ORCID:0000-0001-5621-1390
Cancer management is a priority due to the current trend of increased incidence in this region. Bangladesh is the 9th most populous country in the world having 142 million people. Presently there are 1.3 to 1.5 million cancer patients in Bangladesh. Each year the number of newly diagnosed cancer patients are about 0.2 million. $^{2-3}$ According to GLOBOCAN 2008, the 5-year cancer survival prevalence is 291.2 thousand. $^{4}$ According to the data of National cancer registration and analysis service of United Kingdom, showed that between 2007 and 2009 there were an average of 7,800 endometrial cancer cases diagnosed annually in the UK, making this the fourth most common cancer in women and the 
most common gynaecological cancer. The incidence of endometrial cancer is raising, due to improved screening causing fewer hysterectomies in ageing population. But there is no such data regarding incidence of endometrial cancer registered in Bangladesh.

Diabetes mellitus (DM) is a common chronic diseases characterized by high blood sugar level. According to World Health Organization (WHO) prevalence of DM in 2000 was 171 million and would reach approximately 366 million by $2030 .^{5}$ However, prevalence of DM is increasing day by day and has already reached 346 million as of $2010 .{ }^{4}$ Worldwide high prevalence of DM are mostly related to most of the mortality and morbidity. ${ }^{6}$ Therefore, several studies are going on to find out the association and effects between DM and DM-related diseases, specially DM and cancer. $^{7}$ The American Association of Clinical Endocrinologists and the American College of Endocrinology (AACE/ACE Consensus Statement) emphasized that large and systemic studies should be done to find out the relationship between DM and cancer. ${ }^{8}$

Obesity is a recognized disease in its own right and consequently causing a number of chronic, noncommunicable and life threatening disease including non-insulin dependent diabetes mellitus. ${ }^{1}$

Several studies showed that hyperinsulinemia and insulin resistance, is associated with carcinogenesis and aggressive type of endometrial cancer. ${ }^{9}$ Epidemiologic studies have observed that low adiponectin concentrations a novel endogenous insulin sensitizer, high pre-diagnostic C-peptide concentrations and hyperinsulinemia is associated with increased risk of endometrial cancer.

In humans, adiponectin levels are inversely related to the degree of adiposity and positively associated with insulin sensitivity both in healthy subjects and in diabetic patients. ${ }^{10}$

Plasma adiponectin levels have been reported to be decreased in some insulin-resistant states, such as obesity and type 2 diabetes mellitus. ${ }^{11}$ Moreover, long-term insulin therapy in type 1 diabetic patients may be responsible for increased risk of endometrial cancer. $^{12}$ Obesity and physical inactivity plays important role as modifiable determinants of insulin resistance, hyperinsulinemia, and diabetes.

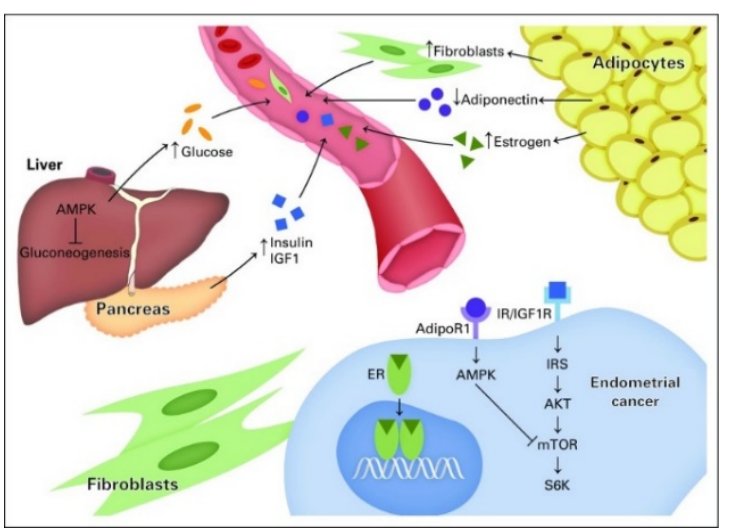

Figure 1: Relationship between diabetes mellitus and endometrial carcinoma

All these factors are also responsible for endometrial cancer. ${ }^{13}$ Several studies have shown positive association between diabetes and endometrial cancer. Very little study available to show association between physical inactivity and endometrial cancer. Furthermore, previously done, there is no such study to show a combined effect of diabetes, obesity, and physical inactivity as a predictor of endometrial cancer. Moreover, previously done very few studies were available, where sample size was very small. Only two prospective cohort studies and four casecontrol studies. ${ }^{13}$

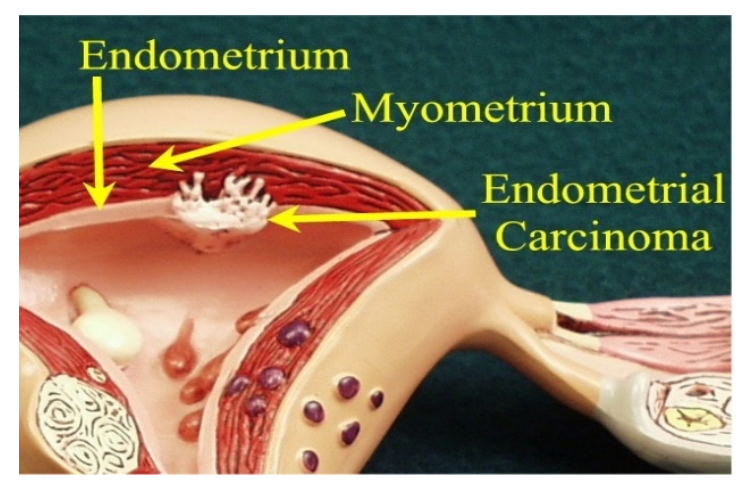

Figure 2: Endometrial carcinoma

Study done by Schouten LJ et al showed that women who spent 90 minutes per day or more doing non-occupational physical activities had a lower risk $(\mathrm{RR}=0.54,95 \% \mathrm{CI}=0.34$ to 0.85$)$ compared with those who spent less than 30 minutes per day. High BMI and low physical activity were strong and independent risk factors for endometrial cancer. ${ }^{14}$

Lot of opportunities to prevent the obesityassociated endometrial cancer. The knowledge of the pathways involved in the pathogenesis of 
endometrial cancer, we should have rational interventions for the prevention. These include potential lifestyle interventions and surgical procedures that decrease visceral adiposity, as well as medications that aim to interrupt or reverse the hormonal and metabolic derangements associated with obesity and insulin resistance.

Public health interventions that decrease the overall prevalence of obesity may have the greatest impact on decreasing endometrial cancer rates in the population. However, lifestyle interventions for weight loss may theoretically reduce a woman's risk for developing endometrial cancer, the data to support this are still lacking. ${ }^{15}$

Obese women have higher levels of estradiol, nonprotein bound estradiol, and estrone than do women of normal weight, and this higher level of hormone is responsible for major reason of endometrial cancer. ${ }^{16,17}$ However, some researchers have argued that in obese women with elevated estrogen levels are not the only cause of endometrial cancer, another factor, such as the higher insulin levels that, may increase the risk. ${ }^{18,} 19$ This study was aimed to assess the relationship of endometrial cancer with obesity, diabetes mellitus and physical inactivity.

\section{Materials and Methods}

This observational cross sectional study was performed over a period of 24 months from January 2015 to December 2017 at the inpatients department of Bangabandhu Sheikh Mujib Medical University (BSMMU) Dhaka, Bangladesh. All female participants admitted at inpatient department of BSMMU, purposively selected until the sample size achieved 100. Fifty consecutive patients admitted as known case of endometrial carcinoma diagnosed by endometrial biopsy and 50 consecutive patients having other gynecological problems were included for this study. The questionnaire was developed based on the information in the literature, regarding risk-factors, common symptoms and signs of endometrial carcinoma. The questionnaire was reviewed by a senior oncologist in our institution. The questionnaire was pre-tested on a convenient sample of 6 women drawn from Bangabandhu Sheikh Mujib Medical University from whom study participants were recruited. Written consent was taken from the parents or their guardians. Ethical clearance was obtained from the IRB of BSMMU. As a result of this pretest, some of the items on the questionnaire have been discarded mostly due to ambiguity of these questions. Some other questions were revised to ensure that vocabulary will be within the comprehension of the study participants. Data were entered in a computer and crosschecking was done to minimise error. Finally, data were analysed to see the association.

\section{Results}

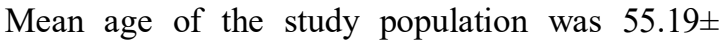
6.783 years. Regarding BMI (body mass index) of the study population it showed that out of 50 women having endometrial carcinoma, only $4 \%$ $(n=2)$ having healthy BMI, 36\% $(n=18)$ were overweight, $60 \%(\mathrm{n}=30)$ were obese. Among 50 healthy women without endometrial carcinoma showed that $4 \%(\mathrm{n}=2)$ having underweight, $70 \%$ $(\mathrm{n}=35)$ having healthy BMI, $14 \%(\mathrm{n}=7)$ having overweight and only $12 \%(n=6)$ were obese. Regarding distribution of diabetes mellitus among study population, 50 women having endometrial carcinoma $26 \%(\mathrm{n}=13)$ were diabetic and $74 \%$ $(n=37)$ were non diabetic. Fifty healthy women without endometrial carcinoma showed that $8 \%$ $(n=4)$ diabetic and 92\% $(n=46)$ were non diabetic. Among total $17 \%(\mathrm{n}=17)$ diabetic patients, $76.5 \%$ (n-13) having endometrial carcinoma and 23.5\% $(\mathrm{n}=4)$ were healthy having no endometrial carcinoma. Among $83 \%(\mathrm{n}=83)$ women having no diabetes $55.4 \% \quad(\mathrm{n}=46)$ were healthy having no endometrial carcinoma and $44.6 \%(n=37)$ having endometrial carcinoma (table I).

Regarding association between diabetes mellitus and endometrial carcinoma Pearson chi squire test showed the $p$ value 0.017 , which is statistically significant. Indicating there is strong relationship between diabetes mellitus and endometrial carcinoma. Linear by linear association between these two diseases also statistically significant. The relative risk (RR) or risk ratio of the endometrial carcinoma having diabetes mellitus was 4.041 (95\% CI: 1.22-13.43).

Risk estimation of women without diabetes and those with diabetes had an adjusted odds ratio of 1.715 (95\% confidence interval $(\mathrm{Cl}: 1.201-2.450)$ for endometrial cancer. 
Table I: Distribution of diabetes mellitus among study population

\begin{tabular}{|c|c|c|c|}
\hline Diabetes mellitus & $\begin{array}{c}\text { Present endometrial } \\
\text { carcinoma }(n=50)\end{array}$ & $\begin{array}{c}\text { Absent Endometrial } \\
\text { carcinoma }(n=50)\end{array}$ & $\begin{array}{l}\text { TOTAL } \\
(n=100)\end{array}$ \\
\hline Present Diabetes mellitus & $26 \%(n=13)$ & $8 \%(n=4)$ & $17 \%(n=17)$ \\
\hline Absent Diabetes mellitus & $74 \%(n=37)$ & $92 \%(n=46)$ & $83 \%(n=83)$ \\
\hline Total & $100 \%(\mathrm{~N}=50)$ & $100 \%(\mathrm{~N}=50)$ & $100 \%(\mathrm{~N}=100)$ \\
\hline \multicolumn{4}{|c|}{ Correlation of Diabetes mellitus with endometrial carcinoma } \\
\hline \multicolumn{2}{|c|}{ Present Diabetes mellitus } & Absent Diabetes mellitus & Total \\
\hline \multicolumn{4}{|c|}{ Present endometrial carcinoma } \\
\hline Count $(\%)$ & 13 & 37 & 50 \\
\hline within CA & 26.0 & 74.0 & 100.0 \\
\hline within DM & 76.5 & 44.6 & 50.0 \\
\hline \multicolumn{4}{|c|}{ Absent Endometrial carcinoma } \\
\hline Count $(\%)$ & 4 & 46 & 50 \\
\hline within CA & 8.0 & 92.0 & 100.0 \\
\hline within DM & 23.5 & 55.4 & 50.0 \\
\hline Total & 17 & 83 & 100 \\
\hline within CA & 17.0 & 83.0 & 100.0 \\
\hline within DM & 100.0 & 100.0 & 100.0 \\
\hline
\end{tabular}

Regarding BMI of study population 36\% $(\mathrm{n}=36)$ having BMI 30 and above, among them $83.3 \%(\mathrm{n}=30)$ had endometrial carcinoma and $16.7 \%(\mathrm{n}=6)$ had no carcinoma. It showed high BMI contributes almost five times more chance of endometrial carcinoma. There is strong association of endometrial carcinoma and obesity, which is statistically significant. Those having high BMI (overweight, obese) and diabetics had significant elevated risks of endometrial cancer, compared with non-overweight non-diabetic subjects.

Table II: Diabetes mellitus and endometrial carcinoma

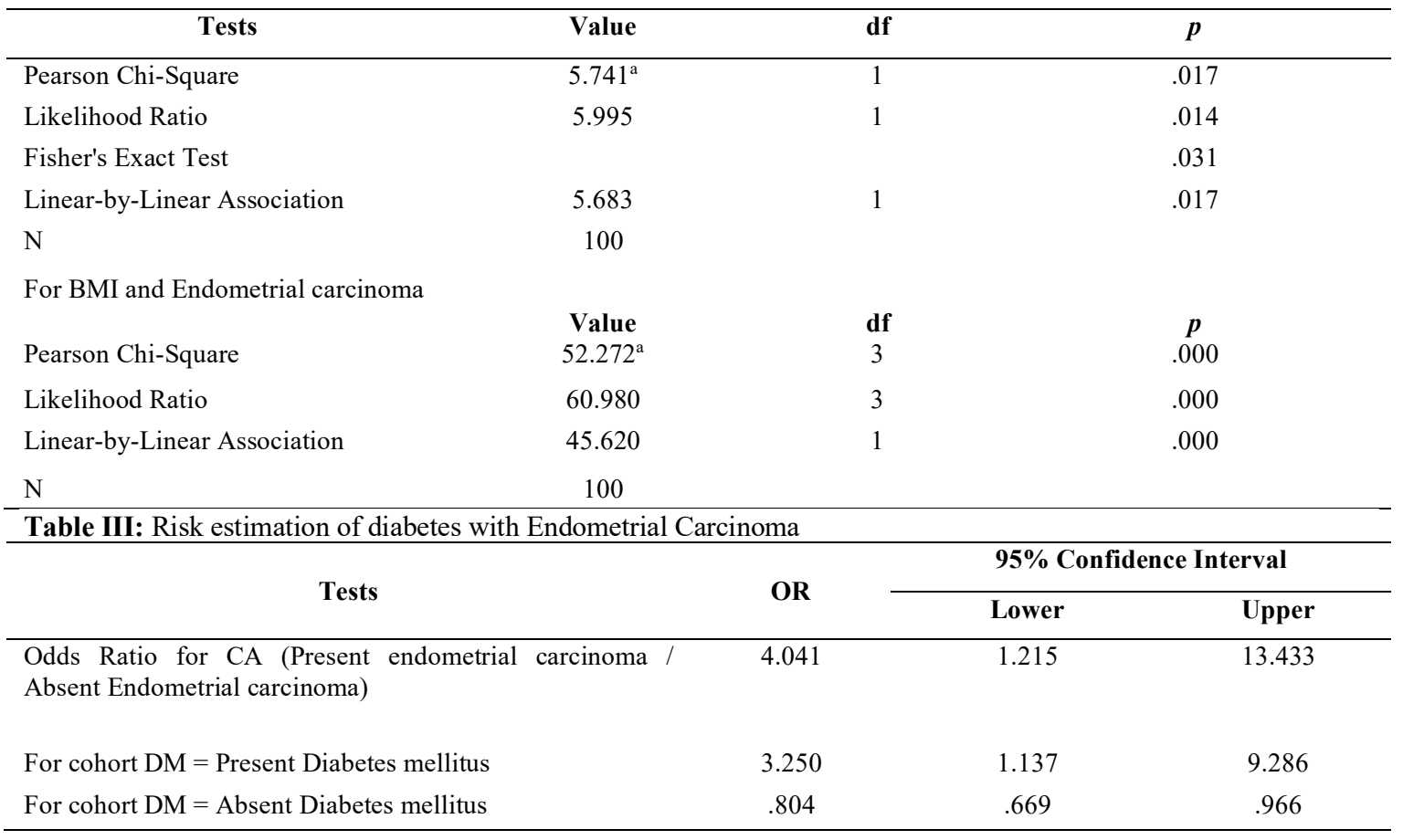




\begin{tabular}{ll}
\hline $\mathrm{N}$ & 100
\end{tabular}

Table IV: Correlation between Endometrial carcinoma and weight

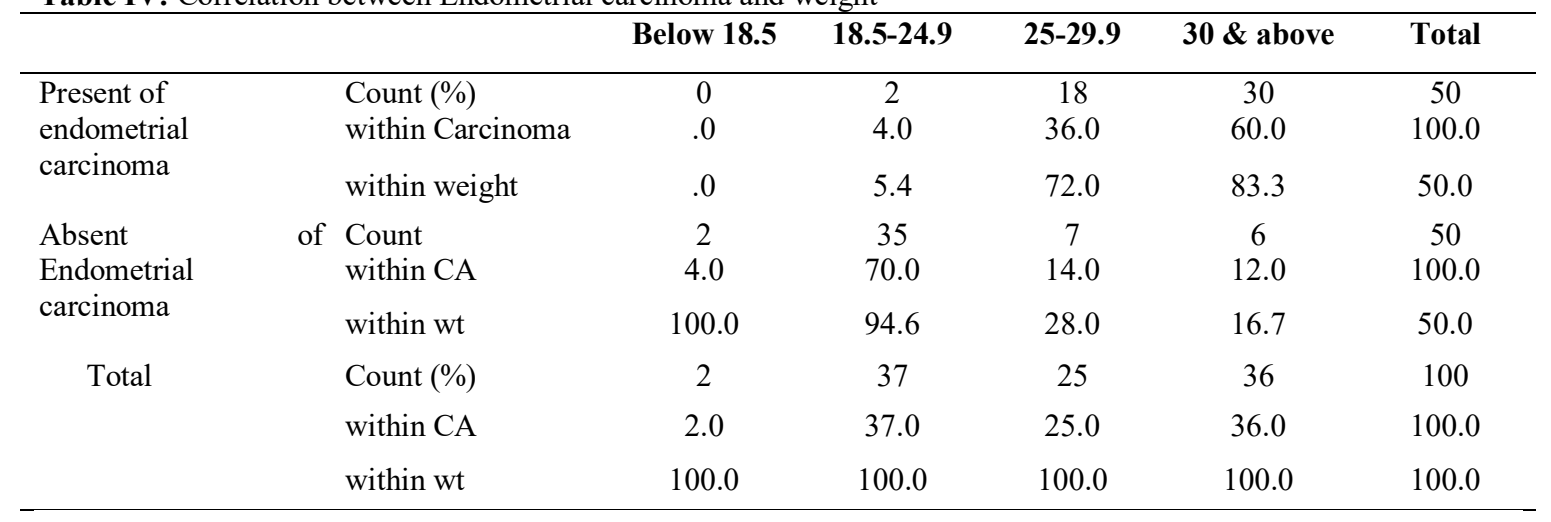

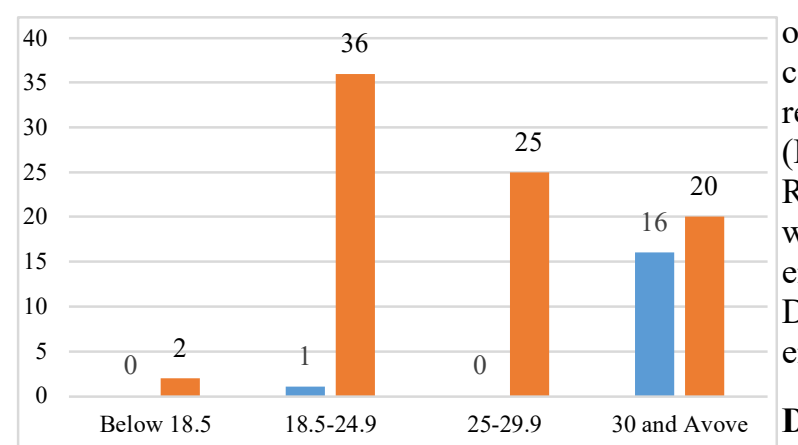

Present of Diabetis Mallietus

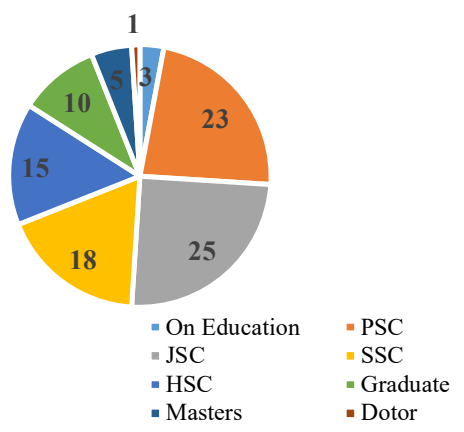

Table V: Binary Logistic Regression

\begin{tabular}{ccccccc}
\hline Variable & B & $\begin{array}{c}\text { Wald } \\
\text { (odd) }\end{array}$ & Sig. & Exp(B) & $\begin{array}{c}\text { 95\% C.I. for } \\
\text { EXP (B) } \\
\text { Lower }\end{array}$ \\
\hline BMI & 2.468 & 25.244 & 0.000 & 11.793 & 4.504 & 30.880 \\
DM & 1.323 & 2.085 & 0.149 & 3.756 & .623 & 22.637 \\
Constant & -9.739 & 11.640 & 0.001 & .000 & & \\
CA (Endometrial Carcinoma) & Cand & $-9.739+2.47$ & BMI (Body \\
Mass Index) + 1.32 DM (Diabetes Mellitus) & \\
\hline
\end{tabular}

From Binary Logistic Analysis it was considered endometrial carcinoma is dependent variable, which is distributed two categories, one is presence of carcinoma and another was absence of carcinoma. It was planned to observe any relationship of BMI (Body Mass Index) and DM (Diabetes Mellitus) with endometrial carcinoma. Regression analysis showed that the patients who were overweight are 2.46 times as likely to turn endometrial carcinoma $(p<0.00)$ and how had Diabetes Mellitus 1.32 times change to had endometrial carcinoma.

\section{Discussion}

Endometrial cancer (EC) is associated with overall good survival rates but women diagnosed with high-risk subtypes like non-endometroid variety have poor outcomes. ${ }^{20}$ There is very limited public awareness regarding the relationship of endometrial cancer and obesity. Obesity is also a risk factor for diabetes mellitus. There was a survey of 1,545 healthy women showed that $58.0 \%$ of the participants were not aware about obesity and its relation of increased risk of endometrial cancer. ${ }^{21}$ Another survey revealed that $46.5 \%$ of the women with endometrial cancer were unaware that obesity was a risk factor for their disease. ${ }^{22}$ Furthermore, health care providers are often not that much enthusiastic to counsel patients with endometrial cancer about obesity. In a separate survey of 108 women with endometrial cancer, only $29 \%$ reported being told by their health care provider about the link between obesity and endometrial cancer. Interestingly, all of the women who were counseled about obesity by their health care providers attempted to lose their weight. Greater public awareness about the association between obesity and endometrial cancer is needed. Public health education and obesity prevention are critical factors to improve the outcomes of endometrial cancer in the years ahead. ${ }^{23}$ 
Sunanda Bharatnur et al mentioned that it is common in post-menopausal women ( $>50$ years) and presents as abnormal vaginal bleeding. About $1-8 \%$ of these carcinomas occur in women less than 40 years. Small numbers of cases have been reported in women under the age of 30 years, the youngest being 15 years. Mean age of the study population was $55.19 \pm 6.783$ years, in present study. Which is similar to previous study. ${ }^{24}$

Friberg E on diabetes and endometrial cancer found that diabetes was statistically significantly associated with an increased risk of endometrial cancer. The risk estimates was RR 2.10, 95\% CI $1.75-2.53 .{ }^{25}$ A total of 22 studies were included in a meta-analysis, of which 9 were cohort and population cohort studies and 13 were case-control and population case-control studies. Of the 22 studies, 14 showed statistically significant associations between diabetes and risk of endometrial cancer. Occurrence of diabetes had an association with increased risk of endometrial cancer $(\mathrm{RR}=1.72,95 \% \mathrm{CI}: 1.48-2.01){ }^{26}$

In present study, the relative risk RR or risk ratio of the endometrial carcinoma having diabetes mellitus is 4.041 (95\% CI: 1.22-13.43). Risk estimation of women without diabetes and those with diabetes had an adjusted odds ratio of 1.715 (95\% confidence interval $(\mathrm{Cl}$ : 1.201-2.450) for endometrial cancer. Regarding association between Diabetes mellitus and endometrial carcinoma in present study showed the $p$ value 0.017 by Pearson chi squire test. Which is statistically significant, indicating there is strong relationship between diabetes mellitus and endometrial carcinoma. Linear by linear association between these two diseases also statistically significant. So present study similar to the study done by Friberg et al.

The American Institute for Cancer Research showed, every increase of five units of BMI, there was a $50 \%$ increase in the risk of developing endometrial cancer (relative risk RR, 1.50; 95\% CI, 1.42 to 1.59$).{ }^{27}$ Renehan et al. found that each increase in BMI of $5 \mathrm{~kg} / \mathrm{m} 2$ significantly increased a woman's risk of developing endometrial cancer (RR 1.59, 95\% CI: 1.50-1.68)3. In a study conducted in the U.K the investigators found that increasing BMI was associated with increased incidence of endometrial cancer having relative risk 10 -units $=2.89,95 \% \mathrm{CI}: 2.62-3.18)$. So, it is obvious that endometrial cancer adversely impacted by obesity. ${ }^{28,29}$
The present study showed distribution of BMI (body mass index) of 50 women having endometrial carcinoma, only $4 \%(n=2)$ normal BMI, 36\% $(n=18)$ overweight, $60 \%(n=30)$ obese. Another 50 healthy women without endometrial carcinoma presented with $4 \%(n=2)$ underweight, $70 \%(n=35)$ normal weight, $14 \%(n=7)$ overweight and only $12 \% \quad(n=6)$ were obese. Regarding association of obese and endometrial carcinoma among total study population $100 \% \quad(n=100)$ women with and without endometrial carcinoma, $36 \%(\mathrm{n}=36)$ having BMI 30 and above, among them $83.3 \% \quad(n=30)$ had endometrial carcinoma and $16.7 \%(\mathrm{n}=6)$ had no carcinoma. It showed high BMI contributes almost five times more chance of endometrial carcinoma. Those having high BMI (overweight, obese) had significant elevated risks of endometrial cancer, compared with non-overweight subjects. Present study results similar to previous studies.

In present study, binary logistic regression analysis was done to see the relationship of BMI (Body Mass Index) and DM (Diabetes Mellitus) with endometrial carcinoma. Regression analysis showed that the patients who were overweight are 2.46 times having endometrial carcinoma $(p<0.00)$ and those are diabetes mellitus 1.32 times having endometrial carcinoma, which are statistically significant. Meta-analysis done by Renehan et al showed the similar results. ${ }^{28,29}$

\section{Conclusion}

Obesity, physical inactivity and diabetes are the risk factors of endometrial carcinoma. So, it should be treated promptly these diseases to reduce risk factors. Moreover, strengthening public awareness to address these risk factors at earliest time to reduce the cancer burden are recommended.

Conflict of interest: Author declared no conflict of interest.

Funding: None

Ethical approval: IRB of BSMMU

Submitted: $13^{\text {th }}$ January, 2020

Final revision received: $27^{\text {th }}$ July, 2020

Accepted: $30^{\text {th }}$ July, 2020

Published: $1^{\text {st }}$ August, 2020

\section{Reference}

1. Rahman SMM, Kabir I, Bhuyan MAH, Akter BMD, Hossain SM. Prevalence and determinants of childhood obesity in Dhaka city. Bangladesh Med Res Counc Bull. 2019; 45:68-80. 


\section{DOI: $10.3329 /$ bmrcb.v45i2.42535}

2. Uddin AK, Khan ZJ, Islam J, Mahmud AM. Cancer care scenario in Bangladesh South Asian. J Cancer. 2013; 2:102-4. DOI: $10.4103 / 2278-330 X .110510$

3. Noronha V, Tsomo U, Jamshed A, Hai MA, Wattegama S, Baral RP, et al. A fresh look at oncology facts on south central Asia and SAARC countries. South Asian J Cancer. 2012; 1:1-4. DOI: $10.4103 / 2278-330 X .96489$

4. Ferlay J, Shin HR, Bray F, Forman D, Mathers C, Parkin DM. Estimates of worldwide burden of cancer in 2008: GLOBOCAN 2008. Int J Cancer 2010; 127:2893-917.

DOI: $10.1002 /$ ijc. 25516

5. P. Zhang, X. Zhang, J. Brown, et al., "Global healthcare expenditure on diabetes for 2010 and 2030," Diabetes Research and Clinical Practice.2015;87:293-301. DOI: $10.1155 / 2015 / 368570)$

6. P. T. Campbell, E. J. Jacobs, C. C. Newton, S. M. Gapstur, and A. V. Patel, "Diabetes and causespecific mortality in a prospective cohort of one million U.S. adults," Diabetes Care, 2012; 35: 1835-44.

DOI: $10.2337 / \mathrm{dc} 12-0002$

7. S. R. Seshasai, S. Kaptoge, A. Thompson, et al., "Diabetes mellitus, fasting glucose, and risk of cause-specific death," The New England Journal of Medicine. 2011; 364: 829-41.

DOI: $10.1056 /$ NEJMoa1008862

8. G. Chodick, A. D. Heymann, L. Rosenmann, et al., "Diabetes and risk of incident cancer: a large population-based cohort study in Israel," Cancer Causes and Control. 2010; 21: 879-87.

DOI: $10.1007 / \mathrm{s} 10552-010-9515-8$

9. Kyong Hye Joung, Jae-Wook Jeong, and Bon Jeong $\mathrm{Ku}$. The Association between Type 2 Diabetes Mellitus and Women Cancer: The Epidemiological Evidences and Putative Mechanisms. BioMed Research International Journal. 2015.

DOI: $10.1155 / 2015 / 920618$

10. Berstein LM, Kvatchevskaya JO, Poroshina TE, et al. Insulin resistance, its consequences for the clinical course of the disease, and possibilities of correction in endometrial cancer. $J$ Cancer Res Clin Oncol. 2004; 130:68793.

DOI: $10.1007 / \mathrm{s} 00432-004-0587-2$

11. Diez JJ, Iglesias $\mathrm{P}$. The role of the novel adipocyte-derived hormone adiponectin in human disease. Eur J Endocrinol 2003; 148:293-300. DOI: $10.1530 /$ eje.0.1480293

12. Zendehdel K, Nyren O, Ostenson CG, Adami HO, Ekbom A, Ye W. Cancer incidence in patients with type 1 diabetes mellitus: a population-based cohort study in Sweden. J Natl Cancer Inst 2003; 95: $\quad$ 1797-800.

DOI: $10.1093 /$ jnci/djg105

13. Kissebah AH, Vydelingum N, Murray R, et al. Relation of body fat distribution to metabolic complications of obesity. J Clin Endocrinol Metab. 1982; 54:254-60.

DOI: $10.1210 /$ jcem-54-2-254

14. Schouten LJ, Goldbohm RA, van den Brandt PA. Anthropometry, physical activity, and endometrial cancer risk: results from the Netherlands Cohort Study. J Natl Cancer Inst. 2004; 96:1635-38. DOI: 10.1093/jnci/djh291.

15. Mulholland HG, Murray LJ, Cardwell CR, et al. Dietary glycaemic index, glycaemic load and breast cancer risk: A systematic review and metaanalysis. Br J Cancer. 2008; 99:1170-75.

DOI: $10.1038 /$ sj.bjc. 6604618

16. Kaye, S. A., Folsom, A. R., Soler, J. T., Prineas, R. J., and Potter, J. D. Associations of body mass and fat distribution with sex hormone concentrations in post-menopausal women. Int. J. Epidemiol. 1991; 20: 151-56. DOI: $10.1093 / \mathrm{ije} / 20.1 .151$

17. Parazzini, F., La Vecchia, C., Bocciolone, L., and Francheschi, S. The epidemiology of endometrial cancer. Gynecol. Oncol. 1991; 41: 1-16. DOI: $10.1016 / 0090-8258(91) 90246-2$

18. Potischman, N., Hoover, R. N., Brinton, L., Siiteri, P., Dorgan, J. F., Swanson, C. A. et al. A case-control study of endogenous steroid hormones and endometrial cancer. J. Natl. Cancer Inst. (Bethesda). 1996; 88: 1127-35. DOI: $10.1093 /$ jnci/88.16.1127

19. Troisi, R., Potischman, N., Hoover, R. N., Siiteri, P., and Brinton, L. A. Insulin and endometrial cancer. Am. J. Epidemiol. 1997; 146: 476-82. DOI: 10.1093 / oxford journals. aje. a009301

20. C.M. Nagle, E.J. Crosbie, A. Brand, A. Obermair, M.K. Oehlerg, M. Quinn, Y. Leung, A.B. Spurdle, P.M. Webb. The association between diabetes, comorbidities, body mass index and all-cause and cause-specific mortality among women with endometrial cancer. J Gynecological Oncology, July. 2018; 150: 99-105.

DOI: $10.1016 /$ j.ygyno.2018.04.006

21. Soliman PT, Bassett RL, Jr, Wilson EB, et al. Limited public knowledge of obesity and endometrial cancer risk: What women know. Obstet Gynecol. 2008; 112:835-42. DOI: 10.1097/AOG.0b013e318187d022

22. Beavis AL, Cheema $\mathrm{S}$, Holschneider $\mathrm{CH}$, et al. Almost half of women with endometrial cancer or hyperplasia do not know that obesity affects their cancer risk. Gynecol Oncol Rep. 2015; 13:71-75. DOI: $10.1016 /$ j.gore.2015.07.002 
23. Clark LH, Ko EM, Kernodle A, et al. Endometrial cancer survivors' perceptions of provider obesity counseling and attempted behavior change: Are we seizing the moment? Int $\mathrm{J}$ Gynecol Cancer. 2016; 26:318-24.

DOI: $10.1097 /$ IGC.0000000000000596

24. Sunanda Bharatnur, Pralhad Kustagi, and Krishnamohan, Endometrial Carcinoma in a Young Woman: "30 is Not Immune" J Obstet Gynaecol India. 2011; 61: 686-88.

DOI: $10.1007 / \mathrm{s} 13224-011-0091-\mathrm{y}$

25. Friberg E1, Orsini N, Mantzoros CS, Wolk A. Diabetes mellitus and risk of endometrial cancer: a meta-analysis. Diabetologia, 2007; 50:1365-74. DOI: $10.1007 / \mathrm{s} 00125-007-0681-5$

26. AlHilli $\mathrm{M}$, et al. The impact of diabetes and metformin on clinical outcomes is negligible in risk-adjusted endometrial cancer cohorts. Gynecol Oncol. 2015; 137:156-57.

DOI: 10.1016/j.ygyno.2015.01.391

27. World Cancer Research Fund/American Institute for Cancer Research: Continuous Update Project Report. Food: Nutrition, Physical Activity, and the Prevention of Endometrial Cancer. 2013. url://discovery.ucl.ac.uk/id/eprint/4841/

28. Renehan AG, Tyson M, Egger M, Heller RF, Zwahlen M. Body-mass index and incidence of cancer: a systematic review and meta-analysis of prospective observational studies. Lancet. 2008; 371:569-78.

DOI: $10.1016 / \mathrm{S} 0140-6736(08) 60269-\mathrm{X}$

29. Reeves GK, Pirie K, Beral V, Green J, Spencer E, Bull D. Cancer incidence and mortality in relation to body mass index in the Million Women Study: cohort study. BMJ. 2007;335:1134 DOI: $10.1136 / \mathrm{bmj} .39367 .495995$. AE 